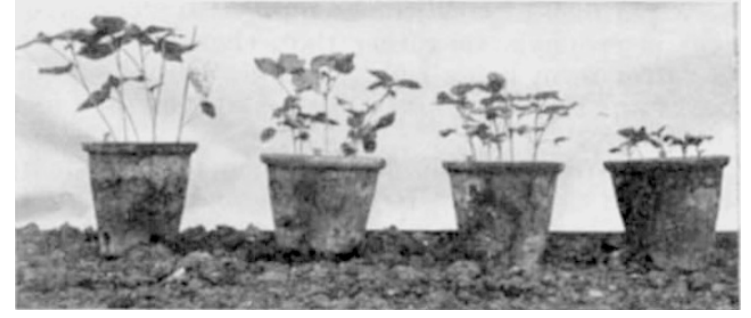

Experiments with a number of other plants and aphids indicate that, as a general rule, the protecting effect varies with the weight of the seed. Good results were obtained with cotton, pea, various beans and nasturtium, which were successfully protected against attacks by aphids and red spider. In some cases a slight stimulating effect on growth has been observed, suggesting utilization of phosphorus by the plant; but soaking at higher strength usually inhibited growth. This inhibiting effect was observed with most plants when the soaking strength was 2 per cent, but nasturtium seeds can tolerate at least 5 per cent without any ill-effect. Small-scale field experiments with peas and beans are at present in progress.

This work was carried out while I was working in Great Britain as a research fellow of Imperial Chemical Industries (China), Ltd. The hospitality of the Imperial Chemical Industries Laboratories at Hawthorndale and the advice and criticism given by members of the laboratory staff are gratefully acknowledged. Thanks are also due to Imperial Chemical Industries, Itd., for permission to publish this work, a fuller account of which will appear elsewhere.

Imperial Chemicel Industries, Ltd.,

Hawthorndale Laboratories,

Jealott's Hill Research Station, Bracknell, Berks, and

Department of Entomology, College of Agriculture,

National Peking University, Peking.

- Schrader, G., BIOS Rep. No. 714 (1948).

2 Ripper, W. E., Greenslade, R. M., and Hartley, G. S., Bull. Ent.

Re8., 40 (4), Greenslade,

${ }^{3}$ Patent protection pending.

\section{Single-Pod Fermentation of Cacao}

MANY aspects of cacao research require assessment of quality of the crop produced by experimental trees, and, as it is obviously desirable that such examination should be made as early as possible in the productive life of the tree, only extremely small samples, often the contents of one or two pods at most, are usually available for examination.

This communication describes a method for the fermentation of the contents of single cacao pods, which has produced very encouraging preliminary results. The method is based on a suggestion of the Cocoa Research Sub-Committee of the Colonial Office.

The apparatus consists of a 10-cm. Büchner funnel, covered with a half Petri dish with a central hole carrying a thermometer. This funnel serves as a fermentation chamber and, in use, its vertical wall is lined with a strip of banana leaf which acts as a heat insulator. The stem of the funnel projects through a rubber stopper into a flask which acts as a receiver for the 'sweatings' resulting from fermentation. This flask in turn is connected to a controlled air supply, and the flask and funnel are contained in a thermostatically controlled electric oven.

A sample of selected healthy beans from one ripe West African Amelonado cacao pod is prepared for fermentation by mixing it with a 'starter', prepared by adding $2 \mathrm{gm}$. dextrose to 10 c.c. of pulp from a large batch of cacao which has been allowed to ferment for $24 \mathrm{hr}$. The sample is then transferred to the funnel, covered with two disks of banana leaf and the Petri dish, placed in the oven and the air supply connected.

During the period of fermentation, moist air is displaced into the bean mass at a rate of $2 \cdot 5-3$ litres per $24 \mathrm{hr}$. Oven temperatures are adjusted as follows :

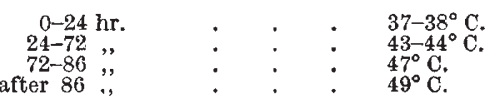

At the end of each 24-hr. period, the beans are thoroughly mixed by hand to secure uniformity of fermentation. Such a procedure does not provide sufficient aeration in the absence of continuous air displacement in the oven. When the predetermined period of fermentation is completed, the beans are removed from the funnel, immediately pricked with a pin to prevent shrivelling during drying and dried in the sun for seven days.

This method has given consistent results, and 100 per cent of fully fermented beans, estimated on their appearance when cut in longitudinal section, can be produced at will.

An independent panel in Great Britain has conducted flavour assessments on beans fermented by this method for four, five and six days and has indicated that samples fermented for five days were the most satisfactory ; those fermented for only four days were under-fermented, while those fermented for six days were tainted by a slight flavour of butyric acid.

My thanks are due to the Director of the West African Cacao Research Institute for permission to make this communication.

\section{J. A. R. MACLEAN}

West African Cacao Research Institute, Tafo, Gold Coast. July 19.

\section{Intracerebral Inoculation of Mice : Fate of the Inoculum}

IT has long been known that a virus may become widely disseminated following intracerebral inoculation into an experimental animal. Thus generalized spread has been found throughout the guinea pig fotus after intracerebral inoculation of influenza virus $^{1}$, vaccinia, tubercle bacilli, and submaxillary gland disease virus ${ }^{2}$; and yellow fever virus has similarly been demonstrated in remote sites after inoculation of the mouse foetus ${ }^{3}$. However, Schlesinger ${ }^{4}$ observed that only 3-10 per cent of the inoculum could be demonstrated in the brains of mice one hour after inoculation, whether equine encephalomyelitis virus or bacteriophage was the test agent, and stated that he was unable to account for 